\title{
OPTIMIZATION OF VEHICLE SUSPENSION KINEMATICS
}

\section{PETR PORTES̆}

Institute of Automotive Engineering, Brno University of Technology, Technická 2, CZ61669 Brno, Czech Republic, Tel.: +420 541142268 , Fax: +420 541143 354, E-mail: portes@fme.vutbr.cz

\section{SHRNUTí konkretizuje jednotlivé dílči úlohy vedoucí k dosažení optimálních hodnot parametrů nápravy. \\ KLIČCVÁ SLOVA: NÁPRAVY VOZIDEL, ZAVĚŠENÍ KOL, KINEMATIKA, OPTIMALIZACE, MULTI-BODY}

Článek popisuje optimalizaci kinematických charakteristik zavěšení kol automobilu. Vypracovaná metoda zohledňuje specifické požadavky na optimalizaci kinematických vlastností nápravy a na proces konstrukčního návrhu a to jak $v$ etapě vývoje před vyrobením prvního prototypu, tak v etapě testování a dolad'ování vlastností vozidla na základě jízdních testů. Príklad aplikace metody

\section{ABSTRACT}

The article presents the optimization of kinematic performance of vehicle suspension. On the basis of the demands on kinematic characteristics and on the design process, a method suitable for optimizing suspension geometry in the stage before the vehicle has been developed. It can also be used for tuning a vehicle's handling behaviour during test procedures. An example shows subtasks that solve specific demands on suspension characteristics and algorithms of their combination to achieve the final optimum.

KEYWORDS: VEHICLE SUSPENSION, KINEMATICS, OPTIMIZATION, MULTI-BODY FORMALISM

\section{INTRODUCTION}

Nowadays, development of a new automobile is largely affected by safety issues. Designers want to construct cars that are safe in the event of a car accident and, at the same time, to minimize the risk of collision through extraordinary driving characteristics. From this perspective, the crucial stage of the vehicle development is the design of the suspension geometry. Geometry of axles affects vehicle behaviour when running straight or through a curve, as well as when braking and accelerating. Axle geometry directly affects force effects acting on the car and thus also its dynamic state, and indirectly it influences the way the driver "feels" the vehicle when driving. Therefore developers evaluate many suspension kinematic characteristics and try to achieve optimum values by modifying its geometry.

Nowadays, classic two-dimensional graphic techniques are obsolete due to the massive utilization of computer-aided design. If they are used at all, their illustrative potential is used in early studies to outline the initial approximate solution. However, nowadays the final design is unthinkable without exact calculations in a 3D environment. Therefore designers most often use generic CAD systems with an implemented module for the kinematic analysis of $3 \mathrm{D}$ mechanisms, generic multi-body programs (e.g. ADAMS, MECHANICA - Applied Motion, DADS) or specialized software for analysis of suspension kinematics. When using CAD systems and multi-body programs, users must create the mechanical model themselves and, at the same time, they have to try to obtain the required kinematic characteristics which is often not easy, particularly with CAD systems. On the contrary, dedicated software is usually made that is capable of computing several types of axles and their kinematic characteristics. Its disadvantage, however, is that the structure of the input data cannot be changed. This makes using these software products difficult, especially when the axle has adjusting elements for the modification of the geometry of an axle whose parameters do not comply with the structure of input data of a given program.

Calculations are often used not only to validate the axle design, but also to improve it. The task is usually formulated in such a manner as to achieve optimum axle kinematic characteristics (often of multiple characteristics) while meeting the conditions for the basic position of the suspension. The basic position is here understood to mean the working suspension position whose vertical displacement corresponds with the straight running of 
the car at a constant speed down a road without any bumps. This, however, entails other difficulties. If the axle geometry changes (even by shifting just one point) due to the modification of one characteristic, not only the characteristic in question, but all other characteristics will be changed. At the same time, the suspension loses its compliance with the predefined conditions in its basic working position. Moreover, software products usually have no tools to quickly adjust the geometry in order to achieve the predefined conditions promptly. Some MB programs are exceptions to this rule, although it is still difficult to create a parametric model that would solve these problems. Instead, a time-consuming process begins after the geometry is adjusted because geometric parameters have to be tailored to predefined conditions through the "manual" editing of positions of points using a trial and error method. And only then is it possible to calculate the kinematic characteristic. Obviously this is an exhausting and lengthy process when you realize that it is necessary to achieve adherence to predefined conditions in a basic working position and ensure the desired behaviour of the kinematic characteristics in dependence on the wheel vertical displacement and steering angle. And what is more, change of geometry can affect one characteristic favourably and another unfavourably.

Appropriate adjustment of the axle cannot be achieved purely through calculations without any testing. Optimum tuning will also be based on test drives whose final results are markedly influenced by how the test driver "feels" the car. Ideally, calculations should therefore be done directly on the polygon during vehicle tests in order to justify the utilization of computer technology. It is necessary to ensure that calculations very quickly (in the order of minutes) provide results that can be used to modify the setup of an axle. The calculations should also be used to gradually obtain individual kinematic characteristics that best correspond with the testing process. Preferably, it should be possible to make the required adjustment to one of the characteristics without affecting the other characteristics. Tests progress much easier when, for example, the height of the axle roll centre can be changed without affecting other kinematic characteristics. Thus we can focus on the change of vehicle behaviour induced by the change of this parameter only. And it is the same with other kinematic characteristics. All these requirements were taken into account when developing the computational process described below.

\section{PROBLEM FORMULATION}

The objective is to optimize the axle so that it meets the predefined requirements in its working position. These requirements usually include wheel vertical position (defined in a variety of ways: distance (height) of the centre of wheel contact with the road from any point on the vehicle body; or length of shock absorber in this position; or distance between two predefined points - one on the wheel disk, the other one on the fender), toe-in, wheel camber, wheel track and wheel base. The optimization process should produce an axle whose kinematic characteristics best comply with design or testing purposes. The basic characteristics include dependences of selected parameters on wheel vertical displacement. They are mainly the dependence of:

1. steering angle on wheel vertical displacement

2. wheel camber on wheel vertical displacement

3. wheel track on wheel vertical displacement

4. height of roll centre on wheel vertical displacement

5. position of pitch centre on wheel vertical displacement

In the case of the front axle, the following dependences are added:

6. caster angle on wheel vertical displacement

7. kingpin inclination on wheel vertical displacement

8. caster offset on wheel vertical displacement

9. kingpin offset on wheel vertical displacement

10. wheel camber on steering angle

11. left steering angle in relation to right wheel (Ackermann geometry)

Furthermore, we monitored possible collisions of certain parts of the mechanism in positions of the mechanism that can occur during the vehicle operation, e.g. collision of the toe rod with surrounding parts, or a change of the drive shaft length exceeding limit values. For details on axle geometry see various technical publications such as [1] etc.

The abovementioned list of requirements does not have to be complete, it depends on the situation. However, it represents a set of characteristics that are very often taken into account when designing the axle. It should be noted then that compliance with all these requirements is not feasible. Moreover, exact criteria for all the above listed dependences on wheel vertical displacement and steering angle are not known. We know rather the tendencies that affect the behaviour in a certain way. Therefore instead of the complete behaviour of the dependence (whole plotted curve) in every characteristic, only selected values such as values in working position and, possibly, the tendency of the whole dependence, are checked out.

As far as the task formulation is concerned, it is better to divide characteristics into those in which the whole behaviour of the dependence (whole curve) will be monitored, and those whose behaviour will be checked "visually" only. Another group will consist of characteristics where only one point of the dependence (of the curve) will be focused on. As this value in most cases corresponds with the basic working position of the mechanism, requirements for this value will be included in the list of basic requirements for wheel suspension in working 
position. By dividing the characteristics in this way, we obtain three areas of calculation that are characterized by parameters, sphere of interest (i.e. what characteristics and what part of their curves are to be focused on), objectives (i.e. what should be achieved) and types of subtasks that are to be solved by appropriately selected computational tools in order to achieve the objectives. Parameters must be selected in such a manner so that all objectives are attainable, and their selection depends on classification of characteristics in individual groups. This classification, however, is not unequivocally defined and depends, to a considerable extent, on the stage of axle development which is aided by computer technology. Below we demonstrate how calculation areas are defined within the process of tuning of axle geometry during vehicle tests.

\section{SUSPENSION MULTI-BODY MODEL}

The front driven McPherson axle was optimized. The mechanism was modelled using SAMS multi-body software developed by the author of this article (for more details see [2]). The low cross arm is connected via two spherical kinematic joints in points $A$ and $B$ with the vehicle body. Point $A$ is the front. In point $C$, the spherical kinematic joint is used to connect the wheel carrier with the arm. The wheel carrier is firmly connected with the steering arm. Both parts together create one body of the model named the wheel carrier. The steering rod (rod constraint) that connects the steering rack with the steering arm maintains constant distance of point $F$ on the steering arm and point $G$ on the steering rack. The strut is modelled by the cylindrical kinematic joint. The model entity point constraint that models the top mount of the damper ensures that the point determining the upper end of the strut coincides at every moment with point $E$ on the vehicle body. The shift of the steering rack against the vehicle body is enabled by the cylindrical joint.

Independent coordinates of the mechanism: $\alpha$ - angle of low cross arm; $\delta$ - steerina rack travel.

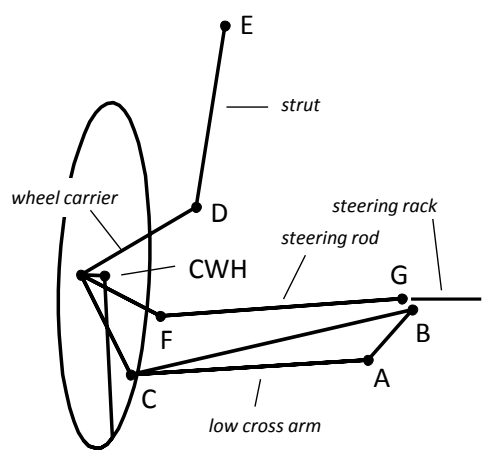

FIGURE 1: Model of McPherson suspension OBRÁZEK 1: Model nápravy McPherson

\section{MULTII-BODY FORMALISM}

As mentioned above, we used SAMS [2] generic multi-body software in order to calculate space mechanisms. This program makes it possible to solve kinematics, statics and dynamics of steady and transition states. For the purposes of this article, we describe below only those parts of generic formalisms that are associated with kinematic analysis, or, to be more precise, with determination of dependence of dependent coordinates on in dependent coordinates of the mechanism.

Modelling elements of the formalism are represented by bodies, kinematic joints, kinematic constraints and force elements. By introducing a kinematic joint into the mechanism structure, the modelling system is supplemented with one body, the appropriate number of relative coordinates $s$, and a set of equations describing mechanism behaviour adequate to connect two bodies of the mechanism by a kinematic joint. The equations describe the position of generic point M of body $i$ (of coordinated system $i$ ) in the basic (fixed) coordinate system

$\mathrm{r}_{0}^{\mathrm{M}}=\mathrm{C}_{0 \mathrm{i}} \times \mathrm{r}_{\mathrm{i}}^{\mathrm{M}}+\mathrm{r}_{0}^{\mathrm{Ci}}$

and velocity ( $\omega^{i}$ angular velocity in the coordinate system $i, \mathrm{v}_{0}^{C_{i}}$ translational velocity of centre of gravity $C_{i}$ of body $i$ )

$\mathrm{v}^{i}=\left(\begin{array}{c}\omega^{i} \\ \mathrm{v}_{0}^{C_{i}}\end{array}\right)=\mathrm{W}^{i} \times \dot{\mathrm{s}}$.

Open kinematic chains are closed via constraint elements that correspond to types of kinematic joints, in which the closed chain was disconnected. With the help of these elements, the mathematical model is supplemented with a system of constraint equations

$f(s, t)=0$.

Their first derivation

$\mathrm{W}_{\text {uz }} \cdot \dot{\mathrm{z}}+\mathrm{W}_{\mathrm{uq}} \cdot \dot{\mathrm{q}}=0$

is used to calculate the first derivation of dependent coordinates $z$ in dependence on the first derivation of independent coordinates $q$. Dependent coordinates for selected independent coordinates can be calculated, for example, using the Newton-Raphson iterative method. The method is based on expansion of equation (4) to the Taylor series in the point of approximate solution. Terms of higher order than one are neglected

$f(\mathrm{q}, \mathrm{z}+\delta \mathrm{z}, t)=f(\mathrm{q}, \mathrm{z}, t)+\mathrm{J} \cdot \delta \mathrm{z}+O\left(\delta \mathrm{z}^{2}\right)=0$,

where Jacobi matrix J equals to matrix $\mathrm{W}_{\mathrm{uz}}$ taken from equation (5). 


\section{OPTIMIZATION ASSIGNMENT - SOLUTION METHOD}

The model is parameterized in such a manner that it is possible to meet the requirements for kinematic characteristics of the suspension and, at the same time, to apply their calculated values on a physically existing (real) axle mechanism. The model parameters are as follows: $A_{x^{\prime}} A_{z}$ (coordinates of point $A$ in the local coordinate system of the vehicle body; $A_{x}$ allows the distance between points $A$ and $B$ to be adjusted to conform with the distance on the low cross arm), $C_{z}$ (height of point $C$ in the wheel carrier's coordinate system), $E_{x^{\prime}} E_{y}$ (coordinates of point $E$ in the local coordinate system of the vehicle body), $F_{z}$ (height of point $F$ in the wheel carrier's coordinate system), $G_{y}$ (coordinates of point $G$ in the local coordinate system of the vehicle body), I (length of steering rod, distance between points $F$ and $G)$. Individual areas of calculation are designed as follows:

\section{CALCULATION AREA I}

Parameters: $\mathrm{A}_{z^{\prime}} \mathrm{C}_{z^{\prime}} \mathrm{E}_{\mathrm{x}^{\prime}} \mathrm{E}_{\mathrm{y}^{\prime}} \mathrm{l},(\alpha-$ to establish the mechanism in the basic working position)

Sphere of interest: Point of dependences 1, 2, 4, 5, 6 (see section 2) Objectives: To achieve required values in the working position for the following quantities: steering angle (see 1), wheel camber (see 2), height of roll centre (see 4), position of pitch centre (see 5), caster angle (see 6)

Subtask types: Solution of system of non-linear equations. Non-linear equation system has the following form

$\mathrm{f}($ parameters $)=0$

where individual elements of vector $f$ have the following form

$f(\text { parameters })_{i}=$ calculated - required

This equation system must include a condition that the wheel vertical displacement corresponds with the basic working position.

\section{CALCULATION AREA II}

Parameters: $\mathrm{F}_{\mathrm{z}^{\prime}} \mathrm{G}_{\mathrm{y}}$

Sphere of interest: Dependence 1 (see section 2)

Objectives: to achieve optimum behaviour of the monitored dependency (whole curve).

Subtask types: Optimization of $\mathrm{n}$-dimensional function with $\mathrm{m}$ parameters. In this case, $\mathrm{n}=1$ and $\mathrm{m}=2$.

General form of the criterion is the following:

krit $=a \cdot \max \left(\Delta_{i}\right)-b \cdot \min \left(\Delta_{i}\right)+\sum_{i} w_{i} \cdot \Delta_{i}^{\mathrm{c}}$

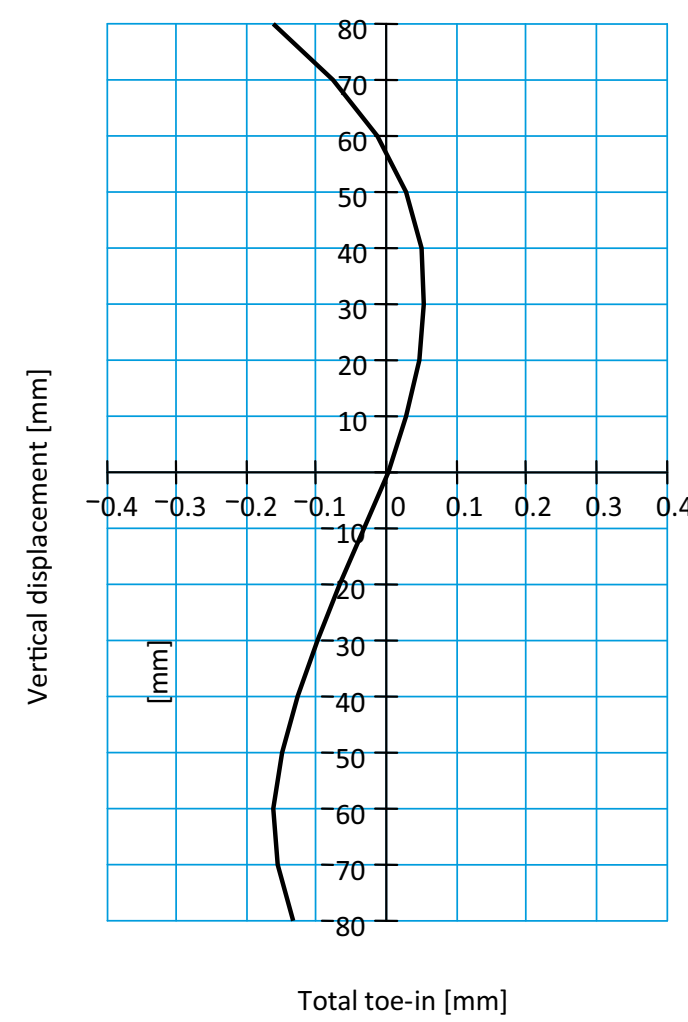

FIGURE 2: Optimized dependence of wheel's toe-in on its vertical displacement

OBRÁzEK 2: Optimalizovaná závislost sbíhavosti kola na jeho zdvihu

where deviation of required behaviour of the dependence is

$\Delta_{i}=$ calculated - required

where $i$ is index of discrete value of a characteristic (dependence, curve) corresponding to $i$-th position of the mechanism.

The criterion is then calculated on the basis of discrete values. Should these values be comparable they must be identified always for the same positions of the mechanism, irrespective of parameter values. Therefore the optimization algorithm has to also include a solution of assignment whose aim is to establish the mechanisms in the set position. This is obtained by solving one non-linear equation. If any of the optimized parameters belongs also to calculation area I, then the system of non-linear equations from area I have to be solved within the optimization algorithm.

\section{CALCULATION AREA III}

Parameters: no parameters

Sphere of interest: dependences 2-11 (see section 2)

Objectives: to obtain kinematic characteristics that will be used to explain the vehicle behaviour or, as the case may be, for checking whether or not the dependence shows undesired behaviour. 
Subtask types: Solution of one non-linear equation. The non-linear equation postulates the requirement for achievement of discrete positions of mechanisms from which graphic representation of dependences being in the sphere of interest are derived. This is the same assignment that is included in the optimization process within calculation area II.

The system of non-linear equations can be calculated using the Newton-Raphson method and optimization can be realized using Powell's method [3]. The result of optimization is demonstrated in Fig. 2. The algorithm of calculation that combines solutions of assignments from individual calculation areas is shown in diagram in Fig. 3.

\section{CONCLUSION}

This article presents optimization of kinematic characteristics of the vehicle axle. The calculation was designed in such a manner as to respect a wide range of requirements arising during the process of vehicle development. These requirements were divided into three categories that are solved in three calculation areas. Calculations from individual areas are combined as appropriate in the resulting algorithm of optimization of geometric design of wheel suspension.

\section{ACKNOWLED GEMENTS}

This article was realized using the subsidization of the Ministry of Education, Youth and Sports of the Czech Republic, research plan MSM 0021630518 "Simulation Modeling of Mechatronic systems".

\section{REFERENCES}

[12] Reimpell, J. \& Stoll, H. (1996). The Automotive Chassis: Engineering Principles. Arnold, London.

[13] Porteš, P. (1997). Mathematical Modeling of Vehicle Handling. Unpublished Doctoral thesis, Brno University of Technology. (in Czech language)

[14] Flannery, B.P., Press, W.H., Teukolsky, S.A. \& Vetterling, W.T. (1986). Numerical Recipes. Cambridge University Press, Cambridge.

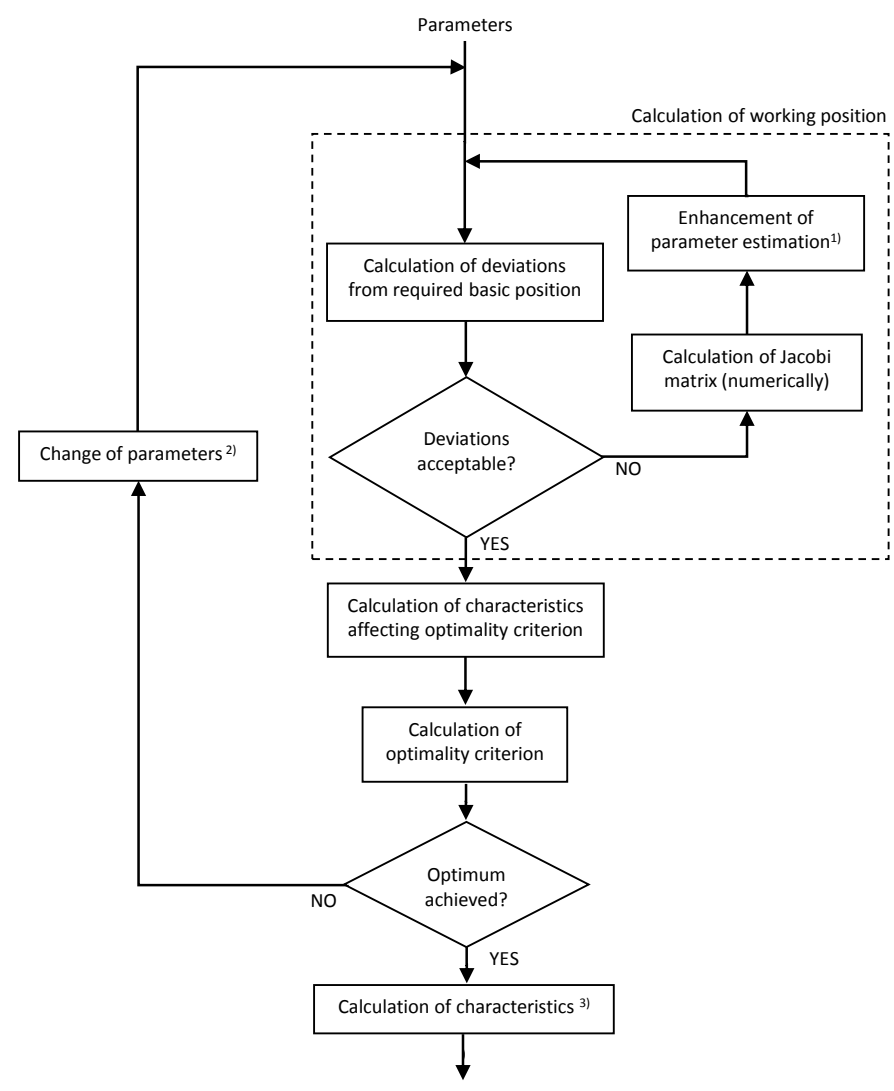

FIGURE 3: Algorithm of optimization of axle kinematic characteristics 1) Parameters from Calculation Area I

2) Parameters from Calculation Area II OBRÁZEK 3: Algoritmus optimalizace kinematických charakteristik nápravy

1) Parametry $z$ výpočtové oblasti I

2) Parametry z výpočtové oblasti II 